\title{
Structure and collective dynamics of liquid sodium
}

\author{
V.N.Patel, P.B.Thakor, B.Y.Thakore, P.N.Gajjar, A.R.Jani \\ Department of Physics, Sardar Patel University, Vallabh Vidyanagar-388120, Gujarat, India
}

Received February 7, 2006, in final form July 3, 2006

\begin{abstract}
The temperature variation of the longitudinal and transverse phonon frequencies of liquid sodium is investigated using the approach by Hubbard Beeby. The molecular dynamics simulation is used to generate the pair correlation function of liquid sodium at various temperatures viz. $T=378 \mathrm{~K}, 473 \mathrm{~K}, 573 \mathrm{~K}$, and $723 \mathrm{~K}$, with 672 particles. To describe the electron-ion interaction our own model potential is employed along with a recent local field correction function due to Sarkar et al. To evaluate the parameter of the potential the zero pressure condition has been applied. The present results of $g(r)$ are in good agreement with available experimental findings. The computed $g(r)$ are used to investigate the temperature variation of the collective dynamics of liquid sodium. The amplitudes of the peaks of the longitudinal and transverse frequencies are suppressed while the width of the propagation gap for the transverse sound waves decreases with an increase in temperature. The computed longitudinal and transverse sound velocities at these temperatures are found to be encouraging.
\end{abstract}

Key words: pseudopotential, pair distribution function, collective dynamics, molecular dynamics

PACS: $71.15 \mathrm{H}, 61.25 \mathrm{M}, 63.20 \mathrm{D}, 71.15 \mathrm{Q}$

\section{Introduction}

A considerable effort has been made over the last four decades to understand the properties of matter through simulations [1-3]. Alkali metals are generally considered to be the simplest metals since they possess a single electron in their external shell. Nevertheless, they are still the objects of great interest [4,5] for different reasons. Their chemical reactivity makes them valuable for researches. The properties of sodium are of interest due to engineering applications and its fundamental significance. The pair-correlation functions $g(r)$, contain useful information about the interparticle radial correlation and structure which in turn decides the electrical, thermodynamical and other physical properties for crystals, liquids and amorphous materials. Several attempts have been made by different workers $[6-15]$ to study the pair correlation function for different metals. In this paper we report a molecular dynamics based study of structure and collective dynamics sodium for various atomic volumes of $277.61 a_{0}^{3}$ at temperature $378 \mathrm{~K}, 285.29 a_{0}^{3}$ at temperature $473 \mathrm{~K}, 292.42 a_{0}^{3}$ at temperature $573 \mathrm{~K}$ and $304.15 a_{0}^{3}$ at temperature $723 \mathrm{~K}$. To describe electronion interactions, a model potential is employed consisting of both linear and quadratic type of interactions within the core $[16,17]$.

We stick to this rather simple model, as it is capable of producing excellent results for other systems $[16,17]$. In $r$-space it has the form:

$$
V_{b}(r)= \begin{cases}-\frac{z e^{2}}{r_{\mathrm{c}}}\left[\frac{3 r}{2 r_{\mathrm{c}}}-\frac{r^{2}}{2 r_{\mathrm{c}}^{2}}\right], & r<r_{\mathrm{c}}, \\ -\frac{z e^{2}}{r}, & r \geqslant r_{\mathrm{c}} .\end{cases}
$$

The corresponding bare ion form factor is

$$
V b_{b}(q)=-\frac{4 \pi z e^{2}}{\Omega_{o} q^{2}}\left[\frac{3 \sin q r_{\mathrm{c}}}{2 q r_{\mathrm{c}}}-\frac{3}{q^{2} r_{\mathrm{c}}^{2}}+\frac{3 \sin q r_{\mathrm{c}}}{q^{3} r_{\mathrm{c}}^{3}}\right] .
$$

The above form tends to give a very weak effect as $r$ approaches 0 and is also continuous at $r=r_{\mathrm{c}}$. The parameter of the potential has been obtained by satisfying the zero pressure condition 
$[16,17]$. This method of determining the parameter is independent of any fitting procedure with the experimentally observed quantities and leads the system to equilibrium with minimum energy.

A more recent and advanced local-field correction function due to Sarkar et. al. [18] is used in the present study in order to incorporate the exchange and correlation effects. The function is,

$$
f(X)=A\left[1-\left(1+B X^{4}\right)\right] \exp \left(-C X^{2}\right),
$$

where $X=\frac{q}{k_{\mathrm{F}}}$. The constants $A, B$ and $C$ are well defined in reference [18].

\section{Pair correlation function}

Here, using the standard molecular dynamic techniques the pair correlation function, $g(r)$ is generated $[1,2]$

$$
g(r)=\frac{1}{n} \frac{\langle\overline{\mathrm{d} n}(r)\rangle}{4 \pi r^{2} \mathrm{~d} r} .
$$

In this expression, $n$ is the number density of the system and $\mathrm{d} n(r)$ is the number of particles within the spherical shell of radius $r$ and the thickness $\mathrm{d} r$ centered around an arbitrarily chosen particle averaged over this origin particle. The notation $\langle\cdots\rangle$ means a time average. Above each particle, concentric radial bins are constructed with a chosen small bin width $\mathrm{d} r$, with the provision that $d r$ is sufficiently small to numerically resolve all the relevant structure in $g(r)$. The number of neighbor's $\mathrm{d} n(r)$ for each particle is counted in each bin. The time average for an MD equilibrium state of $\mathrm{d} n(r)$ is then taken using the standard normalization factor that makes $g(r)$ tend to unity as the correlations tend to zero. When calculating $g(r)$, only that MD iteration was included in the time average where the system remained on the flat portion of the potential energy plateau. These calculations are done for $N=672$ particles and are run for 300 time steps which corresponds to a time of 150 time units or $1.05 \times 10^{-12}$ seconds. The system reaches equilibrium after the first 100 time steps. The equations of motion have been integrated through Verlet's [2] algorithm. The particles are placed randomly in the box and Maxwell's velocity distribution is imposed while invoking the periodic boundary conditions.

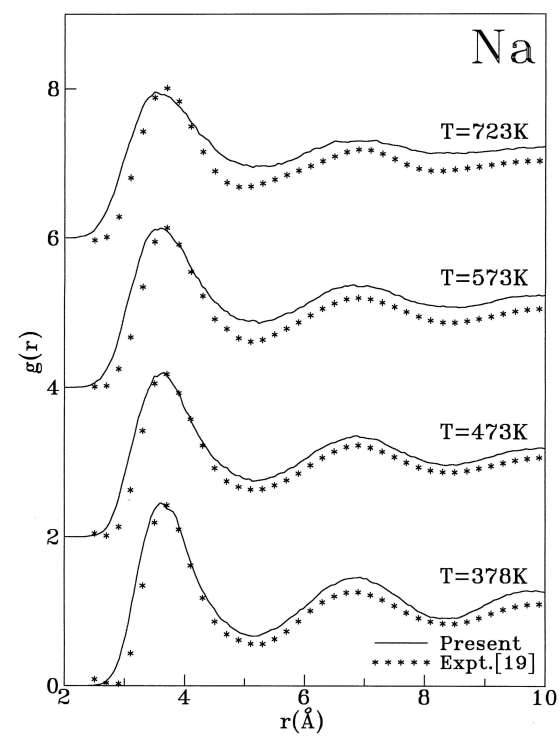

Figure 1. Pair distribution functions $g(r)$ for $N a$ at different temperatures.

The outcome of the presently computed $g(r)$ at different temperatures is shown in figure 1 along with the experimental data [19]. It is observed from the figure 1 that at lower temperatures the crystal shell peaks are seen to appear, indicating that the particles are still oscillating about 
their lattice positions. We also note that there is a strong peak in $g(r)$ at the average nearest neighbour spacing $r$ as would be expected from the fact that $g(r)$ is proportional to the number of particles in a spherical shell a distance $r$ from a given particle. There are other less pounced peaks at average next nearest and further neighbour separations. The radial distribution function depends on density and temperature, and therefore, in computer simulation studies, $g(r)$ serves as a helpful indicator of the nature of the phase assumed by the simulated system. As the temperature increases, the less peaking is seen which indicates that the particles have moved from their lattice positions. At higher temperature the peaking is yet reduced. The molecular dynamic system melts at higher temperature and the particles have enough velocity to move from their perfect crystal lattice positions and diffuse through the system.

\section{Collective dynamics}

Correlation function $g(r)$ obtained by means of MD approach is then used to study the temperature dependency of the longitudinal and transverse phonon frequencies of liquid sodium. The expressions used in computing the squared bare frequencies of the collective excitations without damping are [20] as follows:

$$
\begin{aligned}
\omega_{1}^{2}(q) & =\omega_{E}^{2}\left[1-\frac{3 \sin (q \sigma)}{q \sigma}-\frac{6 \cos (q \sigma)}{(q \sigma)^{2}}-\frac{6 \sin (q \sigma)}{(q \sigma)^{3}}\right] \\
\omega_{t}^{2}(q) & =\omega_{E}^{2}\left[1+\frac{3 \cos (q \sigma)}{q \sigma}-\frac{3 \sin (q \sigma)}{(q \sigma)^{3}}\right]
\end{aligned}
$$

where

$$
\omega_{E}=\frac{4 \pi n_{\mathrm{eff}}}{3 M_{\mathrm{eff}}} \int_{0}^{\infty} g(r) r^{2} V_{\mathrm{eff}}^{\prime \prime}(r) \mathrm{d} r
$$

is the maximum phonon frequency. Here the upper limit of the integration is decided by the length of the MD derived $g(r)$ used in the computations and is $10 \AA$ in the present calculations. $M_{\text {eff }}$ is the effective atomic mass and $n_{\text {eff }}$ is the effective number density while $V_{\text {eff }}^{\prime \prime}(r)$ is the second derivative of the effective pair potential. In the long wavelength limit the phonon dispersion curves show an elastic behavior. Hence, the longitudinal $\nu_{\mathrm{L}}$ and transverse $\nu_{\mathrm{T}}$ sound velocities are also investigated. The isothermal [21] bulk modulus $B_{t}$, modulus of rigidity $G$, Poisson's ratio $\sigma$ and Young's modulus are found using the expressions given below

$$
\begin{aligned}
B_{\mathrm{T}} & =\rho\left(v_{1}^{2}-\frac{4}{3} v_{t}^{2}\right) \\
G & =\rho v_{t}^{2}
\end{aligned}
$$

$\rho$ is the isotropic density of the solid.

$$
\begin{aligned}
\sigma & =\frac{1-2\left(v_{t}^{2} / v_{1}^{2}\right)}{2-2\left(v_{t}^{2} / v_{1}^{2}\right)}, \\
Y & =2 G(\sigma+1) .
\end{aligned}
$$

The general feature of the transverse branch is the existence of a propagating gap at small $q$-values $\left(q<q_{H}\right)$. The width of the propagation gap for the transverse sound waves $q_{H}$ corresponds to a $q$-range where the viscous behaviour of the liquid is dominant over the elastic behaviour and is given by

$$
q_{H}^{2} \approx \frac{\rho G}{4 \eta^{2}},
$$

where the shear viscosity $\eta$ is $q$ dependent. 


\section{Results and discussions}

The effect of increasing the temperature as seen in radial distribution function is that the peaks become broader as the temperature increases. In particular, the height of the first peak decreases gradually whereas its width increases on raising the temperature. Thus the two things observed are the increase in the first peak height and the narrowing of the first peak, which occurs as the temperature is lowered. The other feature is the evolution of the second peak, which occurs with the temperature decrease. The amplitude of $2^{\text {nd }}$ peak increases with the temperature decrease. The results obtained using our own model potential is compared with the experimental values [19] and they are found to be in good agreement around the first peak as well as produces all the characteristic features of $g(r)$ for all $r$. The presently computed $g(r)$ and frequencies reproduce all the characteristic features of the liquid sodium and confirm the use of our model potential in explaining the pair distribution function $g(r)$, as well as the frequencies of collective excitations in liquid sodium. As seen in figure 2 and figure 3 the amplitudes of the peaks of the longitudinal

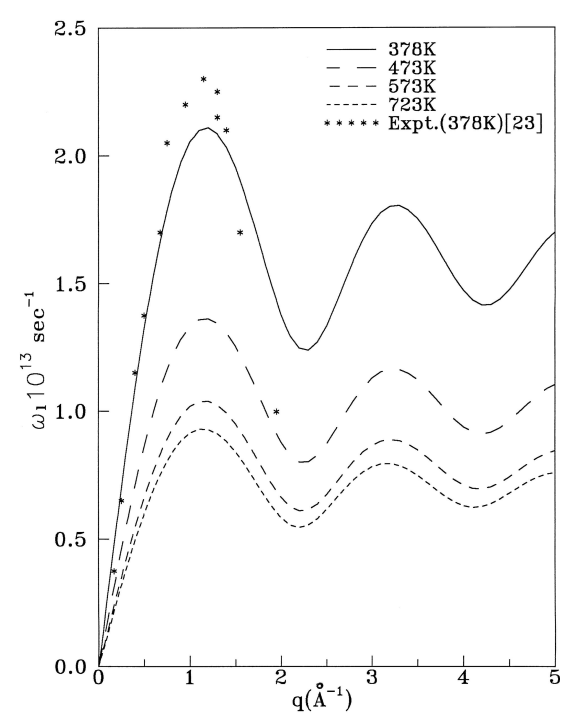

Figure 2. Longitudinal phonon dispersion curves for $\mathrm{Na}$ at different temperatures.

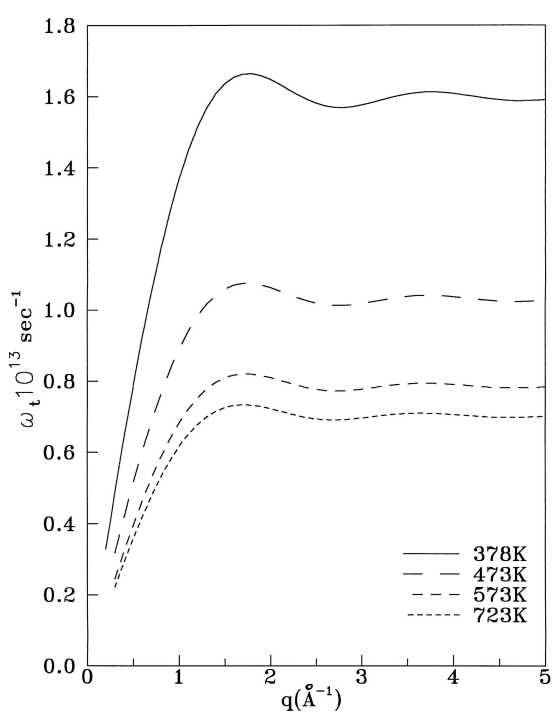

Figure 3. Transverse phonon dispersion curves for $\mathrm{Na}$ at different temperatures.

Table 1. The longitudinal and transverse sound velocities, isothermal bulk modulus $B_{\mathrm{T}}$, modulus of rigidity $G$, Poission's ratio $\sigma$ and Young's modulus and propagation gap of liquid sodium.

\begin{tabular}{|c|c|c|c|c|c|}
\hline \multicolumn{2}{|c|}{ Properties } & \multicolumn{5}{c|}{$T(K)$} \\
\cline { 3 - 6 } \multicolumn{2}{|c|}{} & 378 & 473 & 573 & 723 \\
\hline \multirow{2}{*}{$\begin{array}{c}v_{\mathrm{L}} \times 10^{3} \\
\mathrm{~cm} / \mathrm{sec}\end{array}$} & Present & 3.776 & 3.708 & 3.69 & 3.583 \\
\cline { 2 - 6 } & Expt.[21] & 2.508 & - & - & - \\
\hline $\begin{array}{c}v_{\mathrm{T}} \times 10^{3} \\
\mathrm{~cm} / \mathrm{sec}\end{array}$ & Present & 2.18 & 2.141 & 2.13 & 2.071 \\
\cline { 2 - 6 } & Expt.[21] & 1.814 & - & - & - \\
\hline$B_{\mathrm{T}} \times 10^{10} \mathrm{dyne} / \mathrm{cm}^{2}$ & Present & 7.351 & 6.897 & 6.664 & 6.054 \\
\hline $\mathrm{G} \mathrm{dyne} / \mathrm{cm}^{2}$ & Present & 4.41 & 4.138 & 3.998 & 3.632 \\
\hline$\sigma$ & Present & 0.25 & 0.25 & 0.25 & 0.25 \\
\hline$Y \times 10^{11} \mathrm{dyne} / \mathrm{cm}^{2}$ & Present & 1.103 & 1.035 & 0.999 & 0.908 \\
\hline$q_{H} \AA^{-1}$ & & 0.459 & 0.3786 & 0.3740 & 0.3667 \\
\hline
\end{tabular}

and transverse frequencies are suppressed and the width of the peaks increases with the increase in temperature. The position of the peak is also affected due to the change in the temperature. The 
computed values of longitudinal and transverse sound velocities i.e. $v_{\mathrm{L}}$ and $v_{\mathrm{T}}$, isothermal bulk modulus $B_{t}$, modulus of rigidity $G$, Poission's ratio $\sigma$, Young's modulus $Y$ and propagation gap are shown in table 1 and these values are compared with experimental data available for liquid sodium. It can be seen from table 1 that as the temperature increases the width of the propagation gap for the transverse sound waves decreases. This shows that with the temperature increase the dominance of elastic behaviour increases over the viscous behaviour of liquid sodium. Thus, this potential appears to be a realistic model using which additional theoretical information on the properties of other liquids can be obtained.

\section{Acknowledgement}

The work is supported under DRS/SAP of University Grants Commission, New Delhi, India.

\section{References}

1. Haile J.M. Molecular Dynamics Simulation: Elementary methods. John Wiley Sons, Inc.New York, 1992.

2. Rapaport D.C. The Art of Molecular Dynamics Simulation. Cam. Univ. Press. UK, 2001.

3. Balucani U., Zoppi M. Dynamics of the liquid state. Clarendon, Oxford, 1994.

4. Gonzalez L.E., Gonzalez D.J., Hoshino K., J. Phys.: Condens. Matter, 1993, 5, 9261.

5. Matsuda N., Mori H., Hoshino K., Watabe M., J. Phys.: Condens. Matter, 1991, 3, 827.

6. Gonzalez Miranda J.M., Phys. Lett. A, 1985, 108, 35.

7. Silvestrelli P.L., Alavi A., Parrinello M., Phys. Rev. B, 1997, 55, 23.

8. Bickham S.R., Pfaffenzeller O., Collins L.A., Kress J.D., Hohi D., Phys. Rev. B, 1998, 58, 18.

9. Akinlade O., Ijaduola B.R., Vinvent U.E., Adebayo G.A., Pramana Journal of Physics, 1999, 52, 6631.

10. Clents B.E., Wallace D.C., Phys. Rev. E, 1999, 59, 6.

11. Cabral B.J.C., Martins J.L., J. of Mol. Str. (Thermo chem), 1995, 330, 272.

12. Cabral B.J.C., Martins J.L., Phys. Rev. B, 1995, 51, 872.

13. Day R.S., Sun F., Cutler P.H., Phys. Rev. A, 1979, 19, 328.

14. Murphy R.D., Klein M.L., Phys. Rev. A, 1973, 8, 2640.

15. Mountain R.D., Phys. Rev. A, 1982, 26, 2859.

16. Jivani A.R., Trivedi H.J., Gajjar P.N., Jani A.R., Pramanna-Journal of Phys., 2005, 64, 153; Physica B, 2005, 357, 305.

17. Jivani A.R., Gajjar P.N., Jani A.R., Indian Journal. of Pure and Applied Physics, 2004, 42, 833; Semiconductor Physics, Quantum Electronics and optoelectronics, 2003, 5, 243.

18. Sarkar A., Sen D., Haldar S., Roy D., Mod. Phys. Lett. B, 1998, 12,639.

19. Waseda Y. Structure of Non-crystallineMaterials. McGraw-Hill Pub., Co New York, 1980.

20. Hubbard J., Beeby L., J. Phys. C, 1969, 2, 556.

21. Bryk T., Mryglod I., J. Phys.: Condens. Matter, 2000, 12, 6063.

22. Cocking S.J., Adv. Phys., 1967, 16, 189. 


\title{
Структура і колективна динаміка рідкого натрію
}

\author{
В.Н.Пейтел, П.Б.Факор, В.Я.Факоре, П.Н.Гейдджар, А.Р.Дженай
}

Університет ім. Сердара Пейтела, фізичний факультет Валлабх Відянагор-388120, Гуджарат, Індія

Отримано 7 лютого 2006 р., в остаточному вигляді - 3 липня 2006 р.

За допомогою методу Габбарда-Бібі досліджувалась температурна залежність повздовжньої та поперечної фононних частот рідкого натрію. Парна кореляційна функція рідкого натрію була запропонована при різних температурах, а саме $T=378 \mathrm{~K}, 473 \mathrm{~K}, 573 \mathrm{~K}$ та $723 \mathrm{~K}$, застосовуючи метод молекулярної динаміки для 672 частинок. Опис електрон-іонної взаємодії здійснювався за допомогою запропонованого авторами модельного потенціалу, доповненого функцією Серкара та ін., що описує поправку на локальне поле. Щоб оцінити параметр потенціалу, була застосована умова нульового тиску. Отримані результати для $g(r)$ добре узгоджуються з експериментальними даними. На основі обчисленої $g(r)$ вивчалась температурна залежність колективної динаміки рідкого натрію. Показано, що з підвищенням температури амплітуди максимумів повздовжньої і поперечної частот понижуються, а ширина пропагаторної щілини для поперечних акустичних хвиль звужується.

Ключові слова: псевдопотенціал, парна функція розподілу, колективна динаміка, молекулярна динаміка

PACS: $71.15 H, 61.25 M, 63.20 D, 71.15 Q$ 